

\section{Abstract}

The need for new knowledge about lay representations of contagions, immunity, vaccination, common colds, and influenza has become clear after the $\mathrm{A}(\mathrm{H} 1 \mathrm{~N} 1)$ pandemic and the resulting challenges regarding pandemic preparedness. This article analyzes written responses from 67 persons, mostly women, to a semi-structured questionnaire about colds and the flu. Three themes are discussed: "Common cold and flus as ritualized experiences", "Me, my body, and my immune defense", and "Regulations of space, place, and behaviors." Overall, the narratives were about trust, value, and respect in the body, in lived experiences, and in the capacity to 'help' and 'nurture' the immune system, but also about the feeling of powerlessness when perceiving inadequacies in other people's parallel interpretations and actions. Pandemic preparedness policies need to acknowledge the multiple 'immunity talk' in the responses to create productive, ongoing relations with the 'Other', that rely on people's trust and resilience, rather than on people's fear.

Keywords: common cold; influenza; immune system; pandemics; Sweden 


\title{
The Common Cold, Influenza, and Immunity in Post-Pandemic Times: Lay representations of Self and Other among older people in Sweden
}

\author{
B. Lundgren
}

\section{Introduction}

On the cold winter days during my childhood in the 1950s in the north of Sweden, my mother's voice echoed every time I went outdoors. "Put on your cap, don't forget your gloves - or you will catch a cold". If she was really worried, she warned me about the risk of getting pneumonia. Cold weather was in itself seen as a danger, and dressing accordingly was a way to handle it. Safely out of sight from my mother's eyes, I took off my cap and put it in my schoolbag where it remained until I returned back home.

I have smiled at myself when hearing my own admonitions to my (now grown-up) children, "Put on your cap, you'll get a cold", and I have noticed their own looks of tired reluctance. The warnings have sounded alike through the generations, but the difference would be that I know more about the scientific facts - no, you don't catch a cold from being out in cold weather, there has to be contagion, there has to be a virus, and there are many kinds of viruses. In any case, dressing warmly still seems like good common sense.

In Sweden, the older generations, i.e. those born in 1950 or earlier, have lived through times of many colds, seasonal flus, and the last three pandemic influenzas, and a few of them even lived through the Spanish flu. These generations have also been intermittently subjected to several public health interventions and improvements, including child immunization, school health care, occupational health improvements, hygienic requirements, various kinds of diagnostic screenings, monitoring of risky behaviors, health controls, seasonal influenza vaccination, etc. They have probably caught many colds over their lifetimes, and statistically they will have been afflicted by influenza every fifth year on average (Kucharski et al., 2015).

Surprisingly little is known about how older people in general interpret and handle the kind of diseases that range from the rather trivial common cold to influenza-like illnesses and the life-threatening phases of influenza. The obvious need for this knowledge became particularly clear in face of the $\mathrm{A}(\mathrm{H} 1 \mathrm{~N} 1)$ pandemic, and such knowledge is important for dealing with the challenges regarding pandemic preparedness for the future.

Pandemic influenza is considered to be a recurrent threat to public health and a global issue related to biosecurity, preparedness, and control (Lakoff, 2008; MacPhail, 2010; Lohm et al., 2015), and this places significant demands on public health authorities to react efficiently and responsibly before and during a pandemic. Sweden is one of many Western countries with highly developed pandemic preparedness schemes. These procedures evolved from experiences with the SARS and avian flu epidemics, and efforts to improve these procedures have intensified since 2005 .

For many decades, vaccination has been considered to be the most effective means of fighting both seasonal influenza and new strains of pandemic influenza. The onset of the $\mathrm{A}(\mathrm{H} 1 \mathrm{~N} 1)$ pandemic in June 2009 was a starting point for enacting measures that were planned for in the pandemic preparedness documents. In Sweden, the most important measure was a mass-vaccination intervention that was made possible by an advanced purchase agreement from 2007 with a vaccine producer (Socialstyrelsen, 2011). That the main adult population expected or 
demanded vaccination was more or less taken for granted. The worry was rather that young people would not be willing to get vaccinated, so special campaigns were launched to get attention from these groups. The massvaccination was deemed successful with over 60\% uptake (Socialstyrelsen, 2011).

The $\mathrm{A}(\mathrm{H} 1 \mathrm{~N} 1)$ pandemic turned out to be milder than was initially expected, and the handling of the pandemic - especially the mass-vaccination - has since been criticized for many reasons, including the economic costs, the miscalculation of the disease burden, the 'crying-wolf' that the authorities have been accused of, and most importantly the severe side effects of the Pandemrix vaccine that caused narcolepsy - a lifelong neurological disorder - in 200-300 children and young adults (Medical Products Agency, 2011; Lundgren, 2015a). Taken together, the $\mathrm{A}(\mathrm{H} 1 \mathrm{~N} 1)$ experience and the global issue of pandemic preparedness need to be examined from new angles (Lohm, et al., 2015; HEG Expert Group, 2011), and this means that we need to know more about the general public's representations of contagions, immunity, common colds, and influenza.

Aims

The aim of this article is to investigate how older lay people, mostly women, reflect on the common cold and its relation to influenza and pandemics. How do people perceive the different infections and the immunological reactions they cause? Are common colds and influenza considered as problems to be solved by different strategies or technologies or do they represent something unavoidable (Davis et al., 2015) and inherent in human existence? What kind of measures do people take when on the one hand they are looking inwards - focusing on their own bodies and corporeal immunities (Davis et al., 2015) - and on the other hand when looking outwards on their bodily and spatial interactions with other people, spaces, and places? Does this entanglement of self-perceptions, experiences, recollections, beliefs, and actions have any bearing on pandemic preparedness?

\section{Method}

The material for this article is 67 written responses to a semi-structured questionnaire sent out from a Swedish folk life archive at the Nordiska museet, Sweden's largest museum of cultural history, in Stockholm. These kinds of questionnaires have been used frequently in Swedish ethnological and folkloristic research. As I have discussed in an earlier article (Lundgren, 2015b), the folk life archives have a long history in Sweden and represent the development of the changing roles of their regular contributors. From the beginning of the 1920s, the archives have used the written accounts of people's actual experiences to collect facts about traditional life, but since the 1960s the respondents have been expected to take a more independent position as interpreters of society rather than passive messengers (Klein, 2003). Respondents choose voluntarily if they want to participate in a specific questionnaire or not, and they are free to choose the length and style of writing and may express themselves in whatever way they prefer.

Nordiska Museet has sent out 460 questionnaires on different subjects since 1928. Recent topics have included "Alcohol in my life", "Our monarchy", "Love", "Amateur photography", and "Mass radiography". Today the list of respondents contains 220 persons from all over the country, a majority of whom are women (80\%). Most of them are now quite old and have served as respondents for many years. This particular questionnaire (Nm 243 Common Cold and Flu) was sent out in October 2014. It was constructed by the author and aimed at encouraging people to reflect on issues concerning the common cold, influenza, and pandemics in terms of causes, symptoms, and cures. The questionnaire also provided space for associations and meaning-makings concerning contagions and immunity (Nordiska museet 2014).

There were 67 responses to the questionnaire (30\% response rate) from 58 women and 9 men. The majority (49 women and 7 men) were 65 years or older. They lived in different parts of the country and had various social backgrounds. For the most part, the respondents treated the bio-medically framed questions with great confidence that their life-long experiences would suffice, and this was precisely what was hoped for with the questionnaire. Some of the questions deliberately touched upon complicated biomedical issues such as "How do you think the 
immune system works"? "Where do you think it is 'situated' in the body?" These kinds of questions were designed to make people think of their embodied experiences in a more reflexive way, but it is possible that such questions could at times also make people feel uneducated and stupid (cf. Martin 1994, p12). A few also 'confessed' to having looked some things up in a medical handbook.

\section{Reflecting on the Common Cold and Influenza}

The answers to the questionnaire indicated on the one hand that the topic of colds and the flu were well known and trivial (maybe even boring) to the respondents, and on the other hand that writing caught their interest once they began reflecting on the questions. Thinking and writing about colds and influenza enabled reflections on the body, contagions, and immunity while using "what one knows without knowing that one knows it" (Linger, 2005, p18). These reflections came from their memories of what their parents had told them, what they knew from their earlier experiences, and the experiences of their friends and relatives, and these were added to the biomedically framed knowledge they had gained in one way or another.

I will discuss the following most salient themes in the responses to the questionnaire: 1) Common colds and flus as ritualized common experiences, 2) Me, my body, and my immune defense, and 3) Regulations of place, space, and behaviors.

The first theme comprises common narratives of symptoms, diagnostics, and the course of events in catching a cold or the flu, including suggested remedies and the need to change one's everyday behavior. The second and third themes include discussions about personal responsibilities for keeping oneself fit and healthy and thereby helping one's immune system. These strategies also work to create social and spatial regulations of behaviors - such as hygiene and avoidance - that are connected to morally framed 'othering' processes.

\section{Common colds and the flu as ritualized common experiences}

Everyone has a view on colds and what to do about them (Tyrrell and Fielder 2002:151).

The common cold is a highly prevalent and relatively innocuous group of diseases that are most often selfdiagnosed and self-treatable. Studies have shown that there is a high degree of shared beliefs and explanations about causes for the common cold between lay people and professionals (see Baer et al., 2008, p153). However, some cross-cultural studies have also described lay notions of causality for the common cold that are tied to folk concepts. These include notions such as the hot-cold balance, exposure to dampness or drafts, or exposure to cold after a hot bath or when one has wet hair (Helman, 1978; Baer et al., 2008, p150). Deborah Lupton (2003, p08) has argued that the more common and less serious the illness, the more likely it is that the lay representation is informed by traditional folk concepts. However, in this material, only a few of the respondents talked about cold weather, drafts, or dampness as causal explanations, and the most common explanations fit well with current scientific knowledge. Although there were variations in how the respondents described the cause of the common cold and the flu, most responses talked of how viruses (sometimes they mentioned bacteria instead) resulting in colds or influenza were brought into the body by viral droplets through the air and/or transferred via handled objects ('fomites').

The cold is spread through droplets, when you're sneezing, coughing, etc. through the air. And through contact by handshakes and all the contact you have when you are out among people, in shops, and on public transport. And all the codes that you have to key in - on the small keys there is a whole bunch of bacteria, I guess. It is also good to avoid eating from buffets at times when colds and influenza are common. When I get home I always try to sanitize my hands or wash them with soap and water before I put away my groceries and stuff like that. (KU 20976, woman born 1945).

The respondents had clear opinions about how to recognize the well-known symptoms - the "assorted 
seeping, dribbling, spraying of excessive bodily fluid" (quoted in Greenhough, 2012a, p291) - from colds and flus while reflecting on life experiences reaching back to childhood. The answers provided many examples of diagnosis as a self-performed subjective ritual of disclosure (cf. Rosenberg, 2002, p242):

I notice that a cold is on the march from many things; I get tired, feel poorly, get a small headache, maybe a little fever. I look pallid, my hair is tired, and soon the runny nose [...] If it's influenza I feel much more tired. Muscular pain is usually seen with the flu. [...] Quite soon the coughing starts. I usually cough terribly through much of the night and day. Sometimes I have believed that I would be kicked out from my home because I am so disturbing. I cough so deeply and so loudly. It's awful. And there is mucus, mucus, mucus. I cannot swallow and I don't want to swallow so I spit it out [...] I never see any doctor [...] It will take time and I will endure (KU 20976, woman born 1945).

Colds and flus, like all infectious diseases, are the results of a contagion that comes from the outside. The outside-in movement was apparent in all responses, but also the inside-out transmission when infecting other people. Once the contagion has 'come in' to you, you are 'infected' and a candidate for playing the role of the individual sufferer (Rosenberg, 2002, p242). However, for the common cold both the status of being infectious, a carrier (cf. Newman et al., 2015, p19), and the sickness role were blurred and open to contestation. If you surrendered to being ill and went to bed too early, you could suffer one kind of criticism. Some of the respondents talked about this as a 'male behavior' (cf. Lohm et al., 2015, p121). On the other hand, if you did not mind your symptoms so much and carried on working or meeting with other people you could be criticized for spreading disease. One of the few answers from a younger person, a woman born in 1967, showed her awareness of this avoidance-norm when she described why she went to work as usual as long as she did not have a fever:

I know some of my colleagues get very angry when I come to work coughing, but I usually claim that they are already infected because you are most contagious before the symptoms occur (KU 20972, woman born 1967).

However, this blurriness concerning if, how, and why it was possible to perform a sickness role also created space to make your own decisions and to make the best of your situation. The onset of a common cold created time and space for resting a while, to lie down, and to have a socially accepted reason to be alone and to keep away from people, to have a cozy time. Many respondents described the voluntary rituals surrounding being nice to yourself and interrupting your other daily activities, not because the illness (such as the flu) forced you to, but because a cold invited you to take some rest. ${ }^{1}$

In the evening I can have a really hot bath and lie down in bed with a book and a cup of tea within reach. I turn the light off early and if I am lucky I can sleep for ten hours (KU 20981, woman born 1942).

I often say that I won't get infected, but sometimes it happens that I catch a cold. Then I try to take the opportunity to sleep a little extra, hopefully several times every day. On rare occasions when I have a headache I take a Magnecyl and put on a warm nightcap. Often I get well quite fast. I drink warm milk and make sure I have warm feet and more blankets [...] I think you should help the body to get well by not moving too much (KU 20983, woman born 1929).

\footnotetext{
${ }^{1}$ On a more organized level, this promised land of relaxation and cozyness was used in the British Common Cold Unit when they announced that people should come and join the viral experiments and have a little vacation at a holiday camp (Greenhough 2012, p408).
} 
Some also reflected on the peculiar state of not knowing if one is sick or well:

The common cold is a strange illness because I am not really ill, but not well either, just generally feeling miserable, really miserable [...] I absolutely don't want to stay in bed, because it feels so shabby to lay in bed all day with a cold, but I like to rest on a freshly made bed, by an open window, with a warm blanket and a good book in the afternoon (KU 20966, woman born 1948).

Several cures were mentioned, from different kinds of herbs, fruits, and plants (garlic, ginger, and oranges), to health-enhancing products based on natural remedies (Echinacea, vitamin C) and liquors (cognac, whisky, Jägermeister) (cf. Baer et al., 2008, p160). Quite often these cures were passed inter-generationally, being taught by parents and transferred to children. Several reasons were mentioned for trying them, such as because your mother or father used to do that, because "at least they won't hurt you", and because they experienced that it was possible to influence the course of events and get healthy quicker, i.e. the rituals were vehicles for addressing diseases (Napier, 2002, p22). Some cures were used just because they added to the somewhat cozy experience of being nice to yourself.

Although many studies talk of the uncertainties concerning influenza diagnoses among clinicians (Prior, Evans \& Prout, 2011; Lohm et al., 2015), most of the respondents, when reflecting back on their life experiences, were quite certain how to separate a cold from the flu. The flu is heavier, it 'attacks' you with muscle pain, headache, and fever, simply forcing you to surrender, but with an expectation of recovery: "When you get the flu, you have no choice, you have to rest (KU 20986, woman born 1948)."

Often the causal agents, inhibiting agents, and the means of transmission (cf. Prior et al., 2011. p925) were conflated in the responses. One woman talked of 'bacteria' instead of viruses when describing the 'uninvited intruders' that should be removed as soon as possible, or 'defeated' as she writes, by the white blood cells, but also by herself as a healthy person:

The white blood cells, that hopefully are alert, are doing their job fast and effectively. And I expect that from them because I consider myself to be a healthy and sound human being (KU 20976, woman born 1945).

In the following, I will reflect on the conflation of inhibiting agents and means of transmission and how this is seen through the lens of embodied personal responsibility for body and health, together with what was perceived as the most effective agent - the immune system.

\section{Me, My Body, and My Immune Defense}

During the growth of immunological science, several immunological motifs, metaphors, and models have transcended into the language of discourses of philosophy and other branches of social and cultural theory (cf. Martin, 1994; Napier, 2002; Cohen, 2009; Anderson, 2014). The metaphorical transfer has also taken place the other way around. Ed Cohen has argued that the concept of biological immunity has its roots in a political concept, immunitas, that has been appropriated into biomedical contexts (Cohen, 2009), something that Michelle Jamieson has questioned when discussing politics and biology not as separated but as ontologically entangled (Jamieson, 2015). This is not the place for digging deeply into the vast literature on immunology and its transgressions, but following the work of Martin (1994) I will compare some of the fundamental concepts and distinctions within immunology to what was brought up in the responses to the questionnaire.

Emily Martin wrote in 1994 that the concept of the 'immune system' emerged (Martin, 1994, p16) after an era of increased awareness of hygiene and had "moved to the very center of our culture's conception of health" 
(Martin, 1994, p86). Now, more than 20 years later, the position of the immune system in the center seems to be even more established, even among older lay people without any specific connections to medical education, biomedical professions, or the pharmaceutical industry. Obviously, the respondents to my questionnaire did not distinguish between or reflect on the cellular or bio-physiological immunological functions, but still the immune system took center stage in the descriptions of how to protect oneself from colds and the flu. However, the immune system's relation to the body and to the subjective self were perceived in various ways.

The metaphorical uses of central immunological distinctions, providing cultural meaning-making about what happened in the body, were easy to trace in the responses. One reappearing and culturally reworked distinction is the one that biomedical discourses draw between innate immunity and acquired or adapted immunity. The innate immunity is the first line of defense and consists of the inherited mechanisms of recognition and defense against microorganisms. The adaptive immunity is a specialized system that creates immunological memory after having reacted to a specific pathogen (Janeway et al., 2001). Although some answers reflected on the automatic, inherited, and independently functioning immune system, they put much more effort into describing it as taught, adapted, and dynamic. It was described as not being created at its maximum potential (cf. Martin, 1994, p201) and as something that needed to be nurtured, exercised, and tended to (cf. Davis et al., 2015, p13; Martin, 1994):

Those antibodies circulating in the blood and the functions of the white blood cells to destroy invaders are not equally effective in every person. This differs from individual to individual, and diseases affect us differently. And you have your own responsibility to take care of yourself when disease strikes (KU 20963; woman born 1932).

The nurturing of the immune system provided ways to imagine yourself as a healthy and responsible person who would be able not only to face the trivial colds, but also the more severe flu epidemics and perhaps even pandemics. Imagining immunity (cf. Wald, 2008, p29) in this way meant placing a lot of trust and respect in the immune system, but also in one's own responsibility and capacity (Moore 2010, p101).

However, the distinction between imagining the immune system as something you inherited (innate) and/or as something that you taught and helped (adapted) often collapsed and was transferred into a culturally based metaphorical use of the concept of self/nonself, which since the 1960s has been axiomatic in immunological biomedicine and, although contested, still dominates much of the texts in medical handbooks and in popular medical discourse.

In the responses, there were several varying articulations of self and 'helpers' that indicated profound "sensibilities about the body" (Martin 2004, p33). Sometimes it was 'I' or 'me' acting, sometimes together with 'my body', and sometimes it was just 'the body'. Sometimes the 'immune defense' was included within the concept of 'me' and/or 'my body'. The immune defense could also be seen as an agent working on its own, with or without help from 'me' or 'the body':

Most often I don't get a cold, but I don't know for certain why. I usually look at it as if I have conquered the cold. If I meet someone who has a severe cold, I usually feel sick a couple of days later, but it very seldom breaks out. I guess I have had the infection in my body but have been able to handle it (KU 20958, woman born 1941).

This respondent used the pronoun 'I' to explain that she had conquered the cold by herself, and she did not place any agency in something detached from herself. In another part of her response, she wrote about another ritual she performed when she felt she was getting a cold: she "suns away the cold" by sitting in a sunny spot. Later in the text, her immune system was mentioned as a specific asset, which she was trying to nurture with QiGong every morning and sometimes 'Louhan Patting', fresh air, and sunlight. On the whole, however, she regarded her own self as the most important actor, sometimes with the help from fever, which she separated from herself, and something 
she did not want to act upon: "I want to let the fever have its own way. Fever is a way for the body to fight the infection". In phrasing it like this, she saw 'the fever' and 'the body' as entities to help herself but they were not completely the same as herself.

It was quite common in the written responses to look at oneself in this way, with a continuum from what was regarded as the specific 'I' who acted, to the agency of the 'helpers' - 'the body', 'the fever', or the 'immune defense'. In many answers, these agents were intertwined with and dependent upon responsible action from the 'I':

Building your immune defense is a long process. It depends on what you eat, how you exercise, and also hopefully feeling mentally well. But it is not always that easy. The world is not always good (KU 20963, woman born 1932).

Many answers revealed how people nurtured or helped the immune defense:

The body protects itself against influenza and viruses with a strong immune defense. It is situated in the stomach and you build it up by eating fruits and vegetables. Everything that brings vitamins or minerals is good. You should be outside in the fresh daylight at least 15 minutes every day and exercise at least 30 minutes every day [...] I don't believe in vaccination. You have to endeavor to take care or your body (KU 20975, woman born 1959).

Having a holistic view and engaging in different kinds of therapeutic self-help were also considered to be of help to the immune system:

It is my way of living and it means that for example I don't get stuck in conflicts or negative emotions. I handle things, clear things out, and go on [...] I don't have to spend a lot of energy to defend myself against certain feelings, and consequently I have more energy for all the biological processes that keep the body going, including the immune defense [...] what I am trying to say is that I have a holistic view. You can't really separate body and psyche from each other, not even for something as trivial as the common cold (KU 20980, woman born 1947).

In other responses, the body and the immune defense were specific autonomous actors separated from the 'I':

The body has built its defense, which should protect us from invaders that don't have the right to be there. Where it [the immune defense] sits and how it looks, I have no idea ... I usually don't take any vaccines because I think that the body feels well when it takes care of a cold or an influenza sometimes ... the body has to work, otherwise it stops producing antibodies, because if there is nothing to take care of, why bother to produce them? (KU 20965, woman born 1943)

Many studies have pointed to the militarization of medical thinking, particularly in immunology but also in other medical areas, for example, the "war on cancer" (cf. Martin, 1994; Napier, 2002, 2012). Although it was common in the responses to speak about 'invaders', 'uninvited intruders', 'attack', 'defense', etc., there were also some variations in the metaphorical uses, such as 'patrolling policemen' and hard-working 'small, kind blood cells'.

There were also different opinions on whether vaccination was put into the same military categories or if it was thought of as weakening the immune system. Just as quoted above, many respondents included arguments about vaccination in their perceptions of the function of the immune system. Many people over 65 expressed anger about being put into a 'risk group' after the age of 65 (cf. Evans et al., 2007). Suddenly they got information from the authorities on the need for being vaccinated against seasonal flu. One woman, who was angry about what she 
perceived as an ageist attitude in a "terrible letter in her mailbox" suggesting that she get a flu vaccination, wrote:

Of course it is not the case that your immune defense suddenly changes after a certain date (KU 20980, woman born 1947).

Another woman wrote:

I will soon turn 70, and I absolutely don't regard myself as belonging to a risk group because I am over 65! I feel a bit angry over this careless thinking ... I have trust in my own body and its ability to cure me in the best way. Furthermore, I build up my immune defense every time I get sick. My immune defense, and the white blood cells, who do all the work, are exercised, and this 'training' is lost with vaccination (KU 20976, woman born 1945).

\section{Regulation of Places, Spaces, and Behaviors}

It is well known that pandemics and epidemics cause people to actively reconfigure social and spatial relations (Greenhough 2012a, p282). In my material, the concept of nonself, whether interpreted as microbes or as other people, provided a conceptual tool for the regulation of places and behaviors (cf. Davis et al., 2015, p5).

Although the respondents did not regard the common cold or even influenza to be very serious, normative accounts were presented about how to change your own behavior, i.e. being on the watch for certain places, spaces, and people to avoid. This concerned both the 'othering' of the origins of influenza implying the risk of having contact with foreign places or people, and the othering of problematic behavior where some people were considered not to take responsible action such as having good hygiene or a healthy lifestyle. Sometimes these two were also connected.

The foreign dimension was most apparent when specifically answering questions about pandemics, which were commonly phrased as a consequence of people living close to animals:

These nasty influenza viruses come from Asia where people live close to their domestic animals such as tame birds and pigs (KU 20981, woman born 1942).

This was also said about the swine flu, in spite of the huge media attention to the outbreak of this pandemic in Mexico and California:

I think the swine flu came from Asia. Maybe the bird flu turned into the swine flu. ... Influenza pandemics start in the poor parts of the world (KU 20967, woman born 1938).

One of the questions was how people interpreted the word 'pandemic'. The foreign dimension (Asia, or somewhere South-Eastern, and Africa) was further emphasized in the answers suggesting that pandemics came as a result of an overcrowded earth and were nature's way of handling the problem. The word 'pandemic' was also articulated together with value-laden words such as 'panic', 'something big and dangerous', 'something frightening', 'tsunami', and 'the Black Death'. One person associated the word with the animal 'panther' and one with the animal 'panda' (!). The variations in the answers suggest that there is no absolute and coherent way of interpreting what a pandemic implies. As Abeysinghe (2015, p64) has argued, this also goes for the WHO in their failure to produce a robust definition of 'pandemic' concerning A(H1N1).

The articulation of viruses and contagions together with far-away places also made people consider long airplane flights to be a risk factor - "sit for a long time in a closed space and share expired air with many people" 
(KU 20958, women born 1941). The far-away dimension could also reside at home, which was now correlated to unhygienic behavior:

\begin{abstract}
I was in a store where they sold fresh cakes and pastries that you could pick yourself with a set of tongs that you were supposed to use. I waited for my turn to get apple cakes. In front of me in the queue were a woman and a man. I could not tell what kind of language they spoke. The woman took a cake with her hand and held it in front of the man who shook his head and the cake was put back. They went on until the man nodded. Then I left the queue. I don't want to eat what other people have picked up with their hands. You can't wash a cake (KU 20931, woman born 1937).
\end{abstract}

Obviously, it was important for this woman to mention that she was unable to tell what language the couple in front of her spoke. To her, it was a strange, supposedly far-away language. It was important also to mention that the tongs should have been used, but in this case were not. In telling the story in this manner, she also created a cultural and ethnic othering of un-hygienic behavior. There were also other examples in the responses where this othering was not restricted only to pointing out people from other countries and speaking other languages, but rather emphasizing bad hygienic behavior:

It is easy to observe if you go by subway on an ordinary day during the cold season; almost everyone sits there sniffling, coughing, and sneezing, many directly into the air or into their hands! Instead of into the bend of the arm. I believe that knowledge about contagions among people is incredibly low (KU 20978, man born 1948).

The subway is a place with an extremely high risk for contagions, I think - bad circulation, many people, crowded. Washing your hands after every trip on the subway is a must, and you must also to pull your scarf up over your nose and mouth (KU 20949, woman born 1971).

What to do about the perceived risk of widespread contagions? According to the responses, different measures were taken, including hand sanitizers, wearing gloves, touching door handles with the end of the sleeve, not shaking hands, not touching one's own face, and changing seats or queues to avoid people who are sneezing or coughing.

I was strict with my hand hygiene long before everybody else [...] My habit is to wash my hands with soap and water the first thing I do after taking off my coat. My children have learned this and they have taught their children to do the same (KU 20963, woman born 1932).

Another example was about family lore with talk about relatives who infected others because they did not eat healthy food and, therefore, often caught colds:

I remember a couple of older relatives from the countryside who used to have heavy colds all the time. We guessed that it was because they never ate fruits or vegetables. Probably there were not so many vitamins in their diet. They often infected other relatives (KU 20958, woman born 1941).

The capacity for nurturing the immune system also served as a dividing measure to distinguish responsible people from those who did not play their part in the projects of 'imagining immunities', attending to the logic of social responsibility (Wald 2008, p22), and creating healthy communities. The "unselfconscious embodiments of modes of behavior" (Napier 2002, p76) and the unhealthy lifestyles of other people also caused frustration and "empowered powerlessness", as phrased by Martin (1994, p122). Being a socially responsible individual (Wald 2008, p112), or "response-able" (Greenhough 2012a, p295), for one's own health might not be enough because the 
outcome was also dependent on other people's choices. The strategy of avoiding viruses and bacteria was not the only one described in the answers. Some talked of the wish to engage with the pathogen (because it was good for you and the immune system was exercised), rather than to avoid it (cf. Napier 2002, p21; Davis et al., 2015, p21). Some respondents were quite relaxed and talked of a kind of peaceful coexistence (Greenhough 2012a, p283) with the virus and bacteria and acknowledged the unavoidability of infection (Lohm et al., 2015, p123):

Of course there are contagions, but you can't go around all the time thinking about it. They are everywhere (KU 20979, woman born 1935).

One of the few male respondents went further and expressed the need for exposing oneself to microbes to keep the immune defense working and that one should not interfere in that:

I have no special hygienic rules to protect myself from colds. Instead, I believe in the theory that you should expose yourself to bacteria and viruses to keep the immune defense of the body in shape (KU 20968, man born 1952).

Some also expressed some nostalgic longing for the past during their childhood, where they experienced themselves as being in a necessary relationship with different kinds of germs or viral companions (cf. Davis et al., 2015. p13; Greenhough 2012a, p281). This meant that they did not conceive of this microbial otherness as something principally dangerous (cf. Napier 2012, p128, 130). On the contrary, one woman also regarded the incoming viral cold to be a kind of a "catharsis" for the body and as something to be grateful for (KU 20976, woman born 1945).

\section{Discussion \& Concluding Remarks}

According to Davis et al. (2015. p2), immunity talk is multiple. In this study, this talk included lay interpretations of immunological self/nonself with its implied use of fundamental metaphorical distinctions and sometimes military metaphors, as well as interpretations that are related to modern medicine and that are used to inform public health governance and body politics (Davis et al., 2015, p3).

The respondents placed significant emphasis on what Davis et al. $(2015, \mathrm{p} 3)$ has called 'choice immunity', meaning that subjects were practically and morally responsible for their way of living and that they experienced confidence in how they could help their immune systems to conquer colds or the flu. The self-confidence was shaped like a common-sense life story, nurtured by the homogeneity of the experiences in a life-long perspective together with influences from public health narratives about self-help practices and healthy behavior. The more or less shared models of explanations between the informants and biomedical information (cf. Baer et al., 2008, p61) strengthened the experienced trust. Even influenza-like illnesses and influenza were mostly seen as endurable using a plethora of suggested coping strategies.

The explanatory models about the viral causes of disease also created models for spatial regulation (changing queues, moving away from people who cough and sneeze, wearing gloves, washing hands) or moralizing about relevant behaviors. People used hygiene and infection-avoidance measures while at the same time they tried to cultivate their own immunity as a defense against future viruses (cf. Davis et al., 2015, p2).

The different accounts about colds and flu contained compatible and complementary versions of the self, including the embodied self, the self as narrative, and the autonomous self (Brison 1997, p15). All three versions were entwined in one another, but depending on what kind of explanatory work (Brison 1997, p14) was going on, the respondents emphasized different things in their stories. Whether talking of the self as something distinct from the body or as something identical to the body, the embodied self was given a prominent position in narratives about 
symptoms, resistance, remedies, and recoveries. The ownership of the body and its organs (Church, 1997, p86) was an important theme, showing how they could apply their intentional will to their bodies, or parts of their bodies, such as the immune system, through nurturing, training, and exercising for achieving the utmost efficiency.

In narrating their selves together with their bodies, a dimension of legacy, time, and purposeful agency was added with help from self-regulation and the responsible autonomous self who made choices and decided about actions. Overall, the narratives were about trust, value, and respect in the body, in the immune system (cf. Martin, 1994. p80), in the lived experiences, and in the self, but not always trust in other people's parallel interpretations and behaviors. Many accounts showed how they faced empowered powerlessness in their interactions with other people where they suspected a lack of relational personhood or relational solidarity (Baylis et al., 2008, p5).

As mentioned earlier, most of the responses were from women, which means that it was difficult to analyze if there were any gendered differences. Research has confirmed that the relations between sex/gender and influenza and vaccination are still unclear in many respects. The WHO report "Sex, gender and influenza (2010)" concludes that the precise impact of sex and gender on influenza infection and vaccination is unknown because most studies do not disaggregate data by both age and sex. The WHO report suggests that the outcome of infection is generally worse for women, but the outcome also varies across geographical regions. Differences in hormone concentrations and immune responses together with pregnancy and/or other biological mechanisms seem to have an impact, as do societal and behavioral differences that contribute to differences in exposure (WHO 2010, p37).

Several feminist works on women and health have pointed out the gender dimension as being crucial in understanding health and illness. Of special interest for this study is Sarah Moore's article about the healthy body as gendered (Moore, 2010). In discussing the "new morality of health" she argues that femininity involves a certain attitude toward the body, that the body is essentially uncontrollable, that it is good in and of itself, and that it is synonymous with the self. Sarah Nettleton has argued that the morality of health especially affects women because they are seen as being responsible for initiating healthy lifestyles and for experiencing guilt and worry when they fail (Nettleton, 1996; Moore, 2010, p104). As I have shown from the answers to the questionnaire, this picture can be nuanced. The male answers, although they were few, did not explicitly point to other attitudes toward the body than the women's when it came to handling colds and flu. For men and women alike, the body - and especially the immune system - was in many ways regarded as controllable, and it was hard to find real evidence for gendered norms. A few women mentioned that men were more sensitive to colds and flu, i.e. they gave in to being 'sick' faster than women. This was also pointed out by Lohm et al. (2015) in their discussion about the 'man flu' (p121). But there was also the opposite opinion, stating that it takes a longer time for men to confess to being ill than for women. Regarding female guilt and worry (Moore, 2010), I have not been able to observe anything in this material when it comes to illness experiences of influenza, whether seasonal or pandemic.

By focusing on the responses to the questionnaire, my wish for this article was to be able to contribute to a critical epistemology (Farmer, 2001, p40) about colds and flu. Generally, the material revealed a shared understanding of the common cold that matched the medical understanding (cf. Baer, 2008, p151), as well as shared understandings of what causes influenza and its origins. What seems to differ, however, is that vaccination as a preventive measure was not seen as the grand solution among the respondents, and there were some gaps between the individual experiences of common colds and influenza that counteracted the information campaigns from authorities. The most obvious gap is that, although recognizing the effects that colds and especially flus might have, some had difficulties in seeing themselves as 'frail' people in need of special preventive measures (cf. Cedrachi et al., 2013). As Greenhough has put it, "The common cold is more likely to invoke stoicism than panic" (2012a, p285). This also seemed to be the case when it came to seasonal flu. As I have discussed, the 'immunity talk' was more about how to treat your own health and how to help the immune system to work as good as possible (cf. Prior, 2003, p50).

In face of the $\mathrm{A}(\mathrm{H} 1 \mathrm{~N} 1)$ pandemic in Sweden, the national pandemic preparedness plan emphasized mass- 
vaccination as the dominant conceptual framework and as the most effective measure, i.e. it placed a bio-political intervention ahead of non-pharmaceutical managements such as avoidance and hygiene measures. Although the vaccination had a high uptake, it is not obvious what the exact motivations were for people to comply (see Lundgren, 2015b). In hindsight, when the respondents reflected on the vaccination intervention, the explanation most often was about the fear mongering or the exaggeration of the threat from both the authorities and the media (cf. Lundgren 2015 a, b):

That information about the swine flu was a terrible case of fear mongering. You thought you were facing the Black Death. Did people in the National Board of Health and Welfare believe in this or did they have shares in the pharmaceutical companies? Where is all the vaccine now? Couldn't it be sent to Africa so the poor people down there can be relieved from this flu, then it would be of some use (KU 20982, woman born 1929).

From the responses, it is certainly not obvious that vaccination against influenza would be what people demanded or expected from medical authorities. One sign of this was the irritation about being put in a 'risk group' just because one had reached the age of 65 . In addition, it is not apparent if a certain point was imagined where people would find it necessary to have a vaccination even if it were a pandemic threat.

Lohm et al. have argued that the radical uncertainty about seasonal and pandemic influenza resonates with 'risk society' and can have the "unforeseen consequence of increasing ontological insecurity, that is, weakening people's sense of well-being in the real world" (2015, p117). For this study, my overall impression is that people put trust and faith in their own abilities to cope, not only with different kinds of colds, but also with influenza-like illnesses and influenza. Their emphasis on healthy lifestyles, on ways of helping the immune system, on different remedies and cures, and on the strong faith in recovery all in all pointed to a sense of security and control although they acknowledged that sometimes there could be unavoidable dangers that are inherent in life itself.

I will end with a short outlining of three issues of interest to pandemic preparedness in relation to the public. The first is the use of the word 'pandemic', both from a public-health perspective and from an individual perspective. The different interpretations in this study showed that there were several diverging, and often emotional, associations with the word. A clear and consistent usage of the concept would be beneficial. The second issue concerns the military framings that are commonly used in immunological discourses. Politicians and public health authorities should be careful in framing pandemics and biosecurity into military or hostile terminology, although it might supply "a conceptual bridge between pandemic influenza and biosecurity" (Davis et al., 2015, p4). The cases of excluding and stigmatizing 'others' that I have observed in the responses might be endorsed or enhanced in a way that could prove harmful for pandemic security. A third point would be to elaborate on the findings in the responses pointing to notions of what is termed as 'network immunity' - the idea that the immune system also depends on "productive, ongoing relations with the other" (Davis et al., 2015, p3; Napier, 2012, p121), thereby relying on people's trust and resilience rather than on their fear.

\section{Acknowledgements}

I am grateful to the Nordiska Museet Archive in Stockholm, Sweden, for distributing the questionnaire Nm 243 to their net of corresponding contributors, and I would also like to thank the people who kindly responded to my questions. My gratitude also goes to the Marcus and Amalia Wallenberg Foundation for financing the project "Epidemics, Vaccination, and the Power of Narratives", of which this article is a part. 


\section{References}

Anderson, W. (2014) Getting ahead of one's self? The common culture of immunology and philosophy. Isis, 2014, 105: 606-616.

Baer, R.D.et al. (2008) Cross-cultural perspectives on physician and lay models of the common cold. Medical Anthropology Quarterly, Vol. 22, Issue 2: 148-166.

Baylis, F., Kenny, N.P., Sherwin, S. (2008) A relational account of public health ethics. Public Health Ethics, 1(3): 196-209.

Brison, S.J. (1997) Outliving oneself. In: Meyers, D.T. (ed.) Feminists Rethink the Self. Westview Press: 12-39.

Cedraschi, C. et al. (2013) Representations of influenza and influenza-like illness in the community - a qualitative study. BMC Family Practice 14:15

Church, J. (2997) Ownership and the body. In: Meyers, D.T. (ed.) Feminists Rethink the Self. Westview Press: 85103.

Cohen, E. (2009) A body worth defending: Immunity, biopolitics, and the apotheosis of the modern body. Duke University Press.

Davis, M. et al. (2015) Immunity, biopolitics and pandemics: public and individual responses to the threat of life. Body \& Society. doi 10.1177/1357034X14556155

Evans, M.R, et al. (2007) A qualitative study of lay beliefs about influenza immunisation in older people. British Journal of General Practice 57:352-358.

Farmer, P. (2001) Infection and Inequalities. The modern plagues. University of California Press, CA.

Greenhough, B. (2012a) Where species meet and mingle: endemic human-virus relations, embodied communication and more-than-human agency at the Common Cold Unit 1946-90. Cultural geographies 19(3): 281-301.

Greenhough, B. (2012b) Room with a rhinovirus? Blurring the boundaries between research and a therapeutic space. Transactions of the Institute of British Geographers, NS 37: 402-417.

HEG Expert Group (2011) Science, H1N1 and society: Towards a more pandemic-resilient society. Belgium, Brussels.

Helman, C. (1978) "Feed a cold, starve a fever" - folk models of infection in an English suburban community and their relation to medical treatment. Culture, Medicine and Psychiatry, 2:107-137.

Jamieson, M. (2015) The politics of immunity: Reading Cohen through Canguilhem and New materialism. Body \& Society. DOI 10.1177/1357034X14551843

Janeway, C.A. et al. (2001) Immunobiology $5^{\text {th }}$ Edition. The immune system in health and disease. New York: Garland Science.

Klein, B. (2003) Nm 223. Personlig hygien. Reflektioner kring frågelistor, meddelarsvar och vetenskap. In: Nilsson, B.G, Waldetoft, D., Westergren, C. (eds.) Frågelist och berättarglädje. Om frågelistor som forskningsmetod och folklig genre. Stockholm, Sweden: Nordiska museets förlag: 9-16.

Kucharski A.J. et al. (2015) Estimating the life course of influenza A(H3N2) Antibody responses from crosssectional data. PLoS Biol 13(3):e 1002082. doi:10.1371/journal.pbio.1002082 
Lakoff, A. (2012) The generic biothreat, or how we became unprepared. Cultural Anthropology, 3 (3): $399-428$.

Linger, D.T. (2005) Anthropology through a double lens. Public and personal worlds in human theory. Philadelphia: University of Pennsylvania Press.

Lohm, D., Davis, M., Flowers, P. \& Stephenson, N. (2015) 'Fuzzy' virus: indeterminate influenza biology, diagnosis and surveillance in the risk ontologies of the general public in time of pandemics. Health, Risk \& Society, 17:2: 115-131.

Lundgren, B. (2015a) Narrating Narcolepsy. Centering a Side Effect. Medical Anthropology, Vol. 34, Issue 2, 115-

165. DOI:10.1080/01459740.2014.962694

Lundgren, B. (2015b) "Rhyme or reason?" Saying no to mass vaccination: subjective re-interpretation in the context of the A(H1N1) influenza pandemic in Sweden 2009-2010. Medical Humanities 41:107-112. doi:10.1136/medhum2015-010684

Lupton, D. (2003) Medicine as culture. Illness, disease, and the body in Western societies. Second Edition. London: Sage Publications.MacPhail, T. (2010) A predictable unpredictability. The 2009 H1N1 pandemic and the concept of 'strategic uncertainty' within global health. Behemoth. A Journal on Civilisation. Issue Nr. 3: 57-77.

Medical Products Agency. http://www.lakemedelsverket.se/Alla-nyheter/NYHETER-2011/Rapport-franfallinventeringsstudie-om-Pandemrix-och-narkolepsi/

Moore, S (2010) Is the healthy body gendered? Toward a feminist critique of the new paradigm of health. Body \& Society. Vol. 16(2): 95-118.

Napier, A.D. (2002) The age of immunology. Conceiving a future in an alienating world. University of Chicago Press.

Napier, A.D. (2012) Nonself help: How immunology might reframe the Enlightenment. Cultural Anthropology, Vol. 27, Issue 1: 122-137.

Newman, J.I, Shields, R. and McLeod, C.M. (2015) The MRSA epidemic and/as fluid biopolitics. Body \& Society, doi 10.1177/1357034X14551844

Nordiska museet. Frågelistor. (Questionnaries)

http://www.nordiskamuseet.se/samlingar/insamling/fragelistor/fragelistor-nm-serien

Prior, L. (2003) Belief, knowledge and expertise: the emergence of the lay expert in medical sociology. Sociology of Health \& Illness. Vol. 25 Silver Anniversary Issue: 41-57.

Prior, L., Evans. M.R., \& Prout. H. (2011) Talking about colds and flu: The lay diagnosis of two common illnesses among older British people. Social Science \& Medicine 73: 922-928.

Rosenberg, C.E. (2002) The Tyranny of Diagnosis: Specific Entities and Individual Experience. The Milbank Quarterly, Vol. 80 No. 2: 237-260.

Socialstyrelsen (2011). A(H1N1). An evaluation of Sweden's preparations for and managements of the pandemic. Stockholm, Sweden: The National Board of Health and Welfare.

Tyrrell, D., Fielder, M. (2002) Cold wars. The fight against the common cold. Oxford University Press.

Wald, P. (2008) Contagious. Cultures, carriers, and the outbreak narrative. Durham and London: Duke University Press.

World Health Organization (2010) Sex, gender and influenza.WHO Press. 